\title{
7. Prisoners at Play: Form and Meaning in The Dance of Death and Beckett's Endgame
}

In his finely-argued analysis of the opening pages of part one of Strindberg's The Dance of Death, Egil Törnqvist remarks in passing upon a particularly 'Beckettian segment' of dialogue between the Captain, Edgar, and his wife, Alice. ${ }^{1}$ To read, or better, witness Endgame and The Dance of Death in close proximity yields, however, more than one such passage, and it requires only a little ingenuity to come upon several noteworthy similarities between these two plays both as regards the situations they depict and their language, structure, dramatic method, and underlying themes, that are remarkable enough in themselves to compel the attention of the spectator or reader.

Although these similarities are not on their own account the main subject of this discussion, it is nevertheless useful to provide a basis for an examination of the relationship between theatrical naturalism and absurdist modernism by establishing a number of the most striking of them at the outset. Both plays, for example, commence with tired invitations to play from characters who are confined together with a companion in situations in which time passes only very slowly, and where one of the figures is soon identified as living in the shadow of a death which may at last set his reluctant companion free. 'Won't you play something for me?, Edgar asks [SV 44, 13], to end the silence which succeeds the raising of the curtain upon The Dance of Death, while some three pages later, after several conversational gambits have been tried and found wanting, Alice breaks another long pause by asking the Captain, 'Do you want to play cards?', to which he responds, with little enthusiasm, 'Why not?' [SV 44, 18]. Meanwhile the even older and more weary protagonists of Endgame begin by commenting tonelessly on the current state of play ('Finished, it's finished, nearly finished, it must be nearly finished,' [p. 12]) and then, in Hamm's first words, by informing the audience that it is now 'Me - (he yawns) - to play' [p. 12]. ${ }^{2}$

Immediately afterwards, in The Dance of Death as in Endgame, this opening theme moves rapidly from whatever occasions its dramatic presence in the text (in Edgar's case the piano at which Alice might have eased the atmosphere) to a 
second order meaning of metaphor and suggestion. Behind the surface realism of Edgar's request lie associations with his wife's past as an actress whose career has been cut short by marriage, and to the role-playing in which they both now indulge, while in Beckett's characteristically self-conscious script, Hamm's opening statement is followed by a succession of remarks which, from his early assurance that 'We're getting on' [p. 15] and Nell's query, 'Why this farce, day after day?' [p. 18], to Clov's claim that 'Things are livening up' before an audience he has magnified into 'a multitude... in transports... of joy' [p. 25] and then to the many later allusions to the characters' theatrical predicament ('I'm warming up for my soliloquy' [p. 49], 'Not an underplot I trust' [p. 49], 'This is what we call making an exit' [p. 51]) all monitor the progress of the play and comment upon its own career as a theatrical text. Indeed, Endgame is overtly metatheatrical and engaged, as Ross Chambers observes, in the familiar modern pursuit of providing 'a kind of image of itself, commenting on itself as a play and thus commenting on life itself as theatre. ${ }^{3}$

But Strindberg's apparently naturalistic drama also displays, if only briefly, the acute self-consciousness about its own artistic nature which is normally associated with modernist texts. Just as The Ghost Sonata directs an audience towards its affinity with the fairy tale as a possible means for recuperating what is obviously an innovatory work, ${ }^{4}$ so The Dance of Death likewise defines the terms with which it should be apprehended. These assign it neither to tragedy nor comedy but to the then proliferating genre of grotesque tragi-comedy to which Endgame, with its knowing recognition that 'Nothing is funnier than unhappiness... it's the most comical thing in the world' [p. 20], also belongs. As Kurt remarks, of Edgar, 'He'd be comic if he weren't tragic' [SV 44, 81], and both in his early observations on the need for mirth to alleviate the boredom of living [SV 44,28] and in his concluding speculations on the way in which 'When it's a farce it [life] can be most painful, when it's serious it can be quite peaceful and pleasant' [SV 44, 135], Edgar manifests a contemporary response to experience and the way in which it contravenes traditional artistic categories.

It is, however, primarily the way in which both plays combine surface detail and dialogue with the underlying structure and setting which at first compels comparison and yet eventually permits certain important distinctions to be made. It is, for example, tempting to see The Dance of Death as structurally a prefiguration of the many closed circles of Beckettian drama like the da capo reprise of Play, Krapp's spooling tape, or Godot's affinity with the round song that Vladimir sings at the start of Act Two, in all of which, as Clov remarks, time appears continuously 'the same as usual' [p. 13], and where 'The end is in the beginning and yet you go on' [p. 44]. Moreover, given the way Strindberg's play ends as it began with Edgar alone once more with Alice, in an echo of the opening image, it might even seem apposite to regard the 
Captain's final words, 'Well. Let's go on' [SV 44, 135], as an uncanny preview of Estragon's famous admonition at the close of Waiting for Godot, 'Let's go. (They do not move.).'

This was in fact the effect achieved by Max Reinhardt's famous 1912 production of The Dance of Death at the Deutsches Theater, which opened and closed with Alice and Edgar sitting far apart from each other, motionless and in silence, staring out into nothingness with their backs toward the audience, in a set which accentuated the impression of an earthly hell where people torment each other by extending the stage in a half circle out into the orchestra, so reinforcing the effect of Strindberg's stipulated grey stone circular fortress tower and suggesting the total confinement of the actors within an unbroken circle, in what again evokes the claustrophobic stage image of Endgame. ${ }^{6}$ And while it is certainly true that Reinhardt's mise-en-scène overlooked the fact that in Strindberg's stage directions, the final tableau is actually broken by the Captain who rises to his feet in order to reinforce the urgency of a curtain line which carries the burden of the important inner change he has undergone in the course of the play (he is no longer tired and bored nor fingering a spent cigar, as in the opening tableau, either), it nevertheless conveyed superbly the implication of Strindberg's pithy reformulation of Kierkegaard's notion of repetition, 'Everything comes full circle' [Allt går igen, SV 44, 69], which he had adopted not only as an important element in his later view of life, but also as a principle of dramatic construction. This was notably so in the first part of To Damascus, whose form, according to Strindberg,

symbolizes 'The Repetition' that Kierkegaard speaks of: the action unrolls forward to the Asylum; there it kicks against the pricks and rebounds back through the pilgrimage, the relearning, the eating of one's words, until it begins again at the same point as the action stops, and where it began. [XII, 279; 2, 624]

But the same basic structure is also applied to Crimes and Crimes, in which the settings in the first part are again recapitulated in the second, and to The Dance of Death, which plunges downward into the demonic savagery of Act Two, Scene One, before returning to the relative tranquility of the final scene in which Edgar and Alice, having come to understand that they 'have apparently been condemned to torment each other' [SV 44, 132], prepare (like Beckett's characters) for the liberation death brings, for the moment when, like Clov, they 'will open the door of the cell and go' [p. 51].

Similarly, in their tendency either to return the speakers to silence or to their starting point, the shorter units of stichomythic dialogue into which the text is often divided already foreshadow the highly formal, patterned exchanges of Beckett's couples in both Waiting for Godot and Endgame. And of course the 
Beckettian tone and feel of the text on which Törnqvist remarks (what Beckett, in relation to his own play, has called, 'the power of the text to claw'), 7 is largely fostered by the way in which each speaker has his or her 'repertoire' of stories, memories, or melodies that the other knows by heart, and which are hence incapable of dispelling the fatigue or boredom either of the player or the listener. Each gives the other their habitual cue: 'Just now, when you made the same old reply, "In this house, anyway", I should have replied with my old "it's not just my house"' [SV 44, 30-1], Edgar points out, in recognition of a departure from the familiar script, just as, in the French edition of Endgame, Hamm responds to Clov's 'A quoi est-ce que je sers?' by observing 'A me donner la réplique, ${ }^{8}$ an exchange which emerges as 'What is there to keep me here? / The dialogue' in the English version [p. 39]. Visually confined within the circular fortress or their bare interior, both sets of characters go the rounds of their relationship with well-worn conversational gambits and rapidly exhausted verbal counters in an attempt at securing a temporary advantage over the partner, or opponent, with whom they form, in Mrs Rooney's colourful expression in All that Fall, 'The perfect pair. Like Dante's damned, with their faces arsy-versy', ${ }^{9}$ two creatures who are, as Alice explains, when Kurt wonders why she and Edgar have not parted, 'welded together and can't break free. Once we lived apart - in the same house - for five years. Now only death can part us; we know that, and so we wait for him as our deliverer' [SV 44, 52]. 'All life long the same questions, the same answers,' Clov remarks [p. 13], of this ritual performance of word and gesture, in which dramatic event has virtually given way to the immobility of a situation, 'the end of the day like any other day' [p. 17] where 'we say the same thing every day' [SV 44, 30].

Frequently these gambits end in stalemate as, typically, in the opening segment of The Dance of Death:

CAPTAIN: Won't you play something for me?

ALICE (indifferent, but not crossly): What shall I play?

CAPTAIN: What you like.

ALICE: You don't like my repertoire.

CAPTAIN: Nor you mine. [SV 44, 13)

or from Endgame:

HAMM: Why do you stay with me?

CLOV: Why do you keep me?

HAMM: There's no one else.

CLOV: There's nowhere else.

But occasionally, by the adroit application of the mainly linguistic codes of the game ('Since that's the way we're playing it,' Hamm concludes, 'let's play it 
that way' [p. 52]), one or other player sometimes gains a temporary advantage. For example:

CLOV: Do you believe in the life to come?

HAMM: Mine was always that. (Exit Clov.) Got him that time. [p. 35]

or:

ALICE: I can hear the Alcazar waltz, the melody. Yes, it's some time since I danced a waltz...

CAPTAIN: Could you still manage it?

ALICE: Still?

CAPTAIN: We-ell? You're done with dancing, aren't you, like me?

ALICE: But I'm ten years younger than you.

CAPTAIN: Then we're the same age, for the lady is always ten years younger. [SV 44, 23-4]

Here, the mortal struggle between husband and wife is carried out in language, and points are scored by turning one's opponent's words back upon the speaker, as they often are in Endgame. But behind the thrust and parry of the dialogue in The Dance of Death there is a world of conventional referential meaning which supplies the combatants with ammunition and the social rules of the game ('the lady is always ten years younger'), whereas in Endgame the rules are produced by the power of the text itself to evoke its own world of meaning: 'It'd need to rain', Hamm says; 'It won't rain', Clov replies [p. 13]: move and countermove. As Anthony Easthope observes:

the verbal surface of the play is pervaded by a deliberate artifice, which never allows an audience to forget they are watching a game played according to certain rules.... And a principal effect of the drama derives from the deft manner in which a consciously sustained surface, itself a meaningless exercise in various techniques, is held in tension with the expressive significance of what is suggested beneath it. ${ }^{10}$

It is, however, a surface which the spectator is able to engage with precisely because it seems to adhere to the conventions governing conversation and stage dialogue established in such texts as The Dance of Death.

For however various the underlying motivation behind what the characters say in The Dance of Death, its language assumes the possibility of at least a partial explanation of the action in terms of character and situation, both of which are rooted in what is recognizably the theatrical reproduction of 'everyday' life. Though immensely complex and engaged in uncovering the landscape of another truly infernal domain behind the familiar features of a late-nineteenthcentury household as pointedly as Endgame is with its references to 'the other 
hell' beyond this one [p. 23], Strindberg's text is governed by conventions that are largely realist. What we witness is an action performed by characters who think, behave, and respond to each other in the manner and according to the motivations of people in the world outside the theatre. For the most part, therefore, the codes by which an audience interprets what it sees are taken from its experience and expectations of life, and what it understands to be the appropriate (or merely the dominant) mode of displaying this life on stage. To take one recondite but precise example. When the Captain toys with the notion of 'a broiled mackerel with a slice of lemon and a glass of white burgundy' [SV $44,14-15]$ and asks his wife if it is not the time of year when mackerel are to be caught, the reference to mackerel is sufficient to correct the common assumption that The Dance of Death is set in the Stockholm archipelago which Strindberg knew and loved, and where several other major works (The People of Hemsö, By the Open Sea and parts of A Dream Play) are sited. Mackerel are not fished in the Baltic but on the Swedish West coast, which is thus the correct location for the play. ${ }^{11}$

In Endgame, on the other hand, few such conclusions can be drawn. The text is self-referential, and where it invites, or at least permits, speculation on a meaning or an association which is offered by the page or audible in the theatre, it rarely - if ever -confirms any meaning the reader or spectator may extrapolate, and even then not in terms of a realistic psychological motivation or plot expectation, or as an immediate reflection of the world to which he or she will return at the end of the play, but only as one among many possible meanings implicit in the organization of the text. As Beckett wrote, in a letter to AIan Schneider, 'If people want to have headaches among the overtones, let them. ${ }^{12}$ There is no precise indication of where, or even when, the play is set, and any specific reference like Nagg's allusion to 'the road to Sedan' [p. 19] refers to a past about which it is impossible to be precise. The interpreter is abandoned to a set of associations which cannot be confirmed, but which, in keeping with the catastrophe that brought these characters to their present state, may well evoke memories of 1870 or 1914-18. For whereas in The Dance of Death the focus is first and foremost upon the achieved illusion of characters animated by life, in Endgame the life portrayed is in the words. It is the language to which the characters have been committed that is active and which propagates not only the drift towards meaning which is what those who are forced to use it [p. 32] fear and seek to prevent ('We're not beginning to... to... mean something?', Hamm asks in alarm [p. 27]) but life itself, as on the occasion of the misplaced vowel to which Clov is led by his concern to exterminate the flea:

HAMM: Did you get him?

CLOV: Looks like it... Unless he's laying doggo.

HAMM: Laying! Lying you mean. Unless he’s lying doggo. 
CLOV: Ah? One says lying? One doesn't say laying?

HAMM: Use your head, can't you. If he was laying we'd be bitched. [p. 27]

But notwithstanding this distinction regarding the role played by language in these two plays, The Dance of Death and Endgame nevertheless derive their dramatic effectiveness from similar strategies and to surprisingly similar ends. If the surface text of The Dance of Death appears to reproduce the seemingly random flow of speech in the conflicts of people living together in the social world, according to the notion of dramatic dialogue that Strindberg had developed in the Preface to Miss Julie, where he envisaged stage conversation that 'wanders, providing itself in the opening scenes with material that is then taken up, worked over, repeated, expanded and added to, like the theme in a musical composition' [SV 27, 109], its deep structure already evokes in its subtle choreography of sound and silence, and light and darkness, another dimension. This is not a throwback to the bitter naturalistic universe of The Father and Creditors, ${ }^{13}$ but, like so many of Strindberg's other works from the period following his intellectual and emotional crisis in the mid-1890s, a pre-echo of the purgatorial worlds of Play or How It Is as much as of the marital hell of Who's Afraid of Virginia Woolf. There is in fact a noteworthy consonance between the world of The Dance of Death and Beckett's post mortem landscapes of tormentors and tormented, of figures imprisoned in cycles of sin, guilt and purgation where the real crime (as Strindberg was also inclined to believe) is what Beckett calls 'the original and eternal sin... the sin of having been born.' ${ }^{14}$ All their characters, authorial surrogates, and writers or story-tellers have, of course, committed this crime, and both Strindberg and Beckett compose works in which they or their characters evolve eschatologies of guilt and expiation in order to endow their lives with meaning, to explain the otherwise incomprehensible suffering of their being, or (as one of the voices in That Time puts it) simply 'to keep the void from pouring in on top of you. ${ }^{\prime 15}$ Hence the recurring uncertainty in both writers as to the true nature (infernal or purgatorial) of this world, and the notion that our existence here is a consequence of crimes committed in a previous existence, as Strindberg first conjectures in his autobiographical fiction, The Son of a Servant. Or as Clov phrases it: 'you must learn to suffer better than that if you want them to weary of punishing you - one day' [p. 51]. ${ }^{16}$

This infernal context, which becomes more specific in the course of The Dance of Death, as the seemingly casual early metaphorical references to the hellish life which the inhabitants of the island named 'Little Hell' [SV 44, 109] are leading gain substance in their gradual realization that 'this must be everlasting hell' [de eviga kvalen, SV 44, 134] and must be viewed as such, ${ }^{17}$ is reinforced by the setting. In both plays this offers the spectator a complex visual metaphor of the situation each drama is exploring. Although specific 
details may remain elusive (do the two small windows high up in the wall resemble eyes, and is it therefore the inside of a skull, an echoing chamber of the mind or 'large hollow sphere, hermetically closed to the universe without', such as Murphy conceived in Beckett's early novel, ${ }^{18}$ which is represented on stage?), Endgame is, like many other absurdist works, readily perceived as a concrete stage image, the projection on stage of a powerful inner landscape. But The Dance of Death, no less than the more obviously experimental The Ghost Sonata, which Beckett saw several times in Roger Blin's production at the Gaité-Montparnasse before writing Endgame, ${ }^{19}$ already seeks to express the atmosphere of the inner conflicts by which the characters are possessed through the physical features of the setting, rather than via the immediate naturalist determinism of the environment on character.

In this respect the circular granite island fortress is only nominally a straightforward realistic location. Whereas in his naturalistic dramas Strindberg had often been content with the trappings of a relatively poor theatre (Creditors, he told a publisher with well-placed enthusiasm, would require only 'three characters, a table and two chairs, and no sunrise' [VII, 105; $1,281])$, the unusually careful and specific stage directions for The Dance of Death conjure up an image that is essentially the crux of the situation depicted in the play. The curtain rises upon the red light of the setting sun glinting on the sabre of the sentry on watch outside the window. That he is there to guard those within as much as to protect them from a threat from without is a possibility which Edgar's reference to 'Baron Bluebeard with the maiden in his tower. And outside the sentry marches up and down with his sabre drawn, to guard the fair virgin' [SV 44,59] later confirms. It is an evening in autumn ('Outside and in,' as the Captain lugubriously remarks [SV 44, 14]), and the surrounding sea is calm and still, although the gun batteries pointing out across it invite the supposition that they may be defending those within from a hostile force without. Taken together what is being evoked in a multiplicity of ways is the fact of ageing, or extinguished vitality, and the imminent threat of death, not least in the appearance of the ailing Captain, who at the outset offers an image of impotent manhood. He has laid aside his parade uniform and is now dressed in a worn, undress uniform and fingering a burnt-out cigar, all libidinal passion seemingly spent. Situated on the margin between land and sea, or life and death, the tower is thus a precarious last post where the Captain is poised for departure on that final journey which Strindberg often portrayed in terms of a sea voyage. In The Ghost Sonata, The Pelican and the late dramatic fragment Toten-Insel (1907), for example, one or more of the principal characters embarks from life to death by way of water on a voyage that Strindberg represents both in personal terms, as an escape by steamer from the contamination of earthly life in the corrupting city to the islands of 
the Stockholm archipelago, and through the traditional image of the deceased being ferried to rest in Arnold Böcklin's celebrated painting of 'The Isle of the Dead', which provided, in reproduction, part of the decor of the Intimate Theatre where these plays were first performed.

Again, a comparison with Endgame, in which Hamm and Clov wait for the moments 'to mount up to a life' [p. 45], confined in a room where they watch their 'light dying' [p. 17], inevitably suggests itself, and indeed the life lived in the two beleaguered interiors offers similar accounts of reduced circumstances, in which the Burgundy, the food, and the servants in The Dance of Death, disappear like the pap, bicycles, pain-killers and biscuits in Endgame. It is likewise a world where sight is fading [SV 44, 16] and people have forgotten how to count [SV 44, 20], a world, in short, that is approaching extinction, the void which Edgar identifies as ending everything early on in the play [SV 44, 15] resembling the 'corpsed' [p. 25] universe of Endgame. Nevertheless, it is a world where, like several of Beckett's characters, including Winnie in Happy Days, he continues to recall moments of fleeting pleasure ('but we had our fun now and then' [SV 44, 15]) and days of earlier happiness: 'Those were our happiest days, in spite of everything' [SV 44, 23].

These or other likenesses between The Dance of Death and Endgame have obviously not entirely escaped earlier commentators. It is often pointed out how many absurdist plays also depict a situation in which man is imprisoned in a friendless universe where he is spiritually and physically isolated, bored, and yet unable to communicate with the companions to whom he is hellishly bound in an ambivalent love-hate relationship. ${ }^{20}$ In Strindberg's Impact on France, for example, Anthony Swerling sees Endgame as one in a group of plays (the others are Sartre's Huis clos, Ionesco's Les Chaises and Vauthier's Capitaine Bada) which form what he calls

a cycle of sequestration characterized by the confrontation and collision of the couple, by loneliness and monotony, exhaustion alternating with passion, mental cruelty and incompatibility, the framework of which can be traced back to the tightly-chambered crepuscular anguish of Edgar and Alice. ${ }^{21}$

Moreover, with his customary hyper-sensitivity to a possible echo of a Strindberg text in any modern French drama, Swerling goes on to presume and catalogue a series of additional points of contact between the two texts which suggest that Beckett, like every other dramatist writing in French between 1920 and 1960 , must have spent years in the close textual study of Strindberg.

The essential point of any convergence between the two texts lies, however, not in the opportunity to claim, as Swerling does, an influence where there is only meaningless coincidence ${ }^{22}$ but for what it may reveal of one of the major 
developments which drama undergoes between the late nineteenth century and the present. Or to put it more exactly, the process whereby Naturalism, as the last movement in drama to accord unequivocal status to plot, language and character (and even then, as the Preface to Miss Julie reveals, to dissolve the last of these into an unstable, discontinuous mosaic wherein character is the product of impersonal forces and the discourses which flow through it), gives way to a modernist theatre of stage image and theatrical metaphor. What is at issue here is that inward turn common to a large part of modern drama, in which a loss of confidence in spoken language and the move towards reviving concrete theatrically-specific modes of expression take place at the same time as the portrayal of external social reality is supplanted by the projection onto the stage of inner states of being. It is where a drama based on traditional notions of plot and character is superseded by a thematically organized theatre of situation, in which the discursive narrative element has been largely replaced by a static theatre of images, of scenic metaphors which appeal to the subconscious rather than to the conscious mind. In short, that crisis wherein drama, or at least the post-Renaissance notion of drama as the direct and objective presentation in dialogue of events unfolding in a recognizable world at the moment of performance, is placed in doubt (and indeed, there is barely an account of Beckett's theatre, particularly of the later works, which does not allude to the ways in which it questions the very possibility of drama).

For unlike the novel, which readily accommodates the late-nineteenthcentury turn towards inwardness, where intensity of suffering substitutes for action and man's isolation from his fellows may be portrayed precisely by the ability of the genre to trace a private consciousness in its personal and secluded response to the world, drama, which customarily focuses relations to the external world through the interplay of a character's responses to other men or women, and which depends therefore upon the ability of spoken language to convey both the burden of these relations and a character's private thoughts, is placed under greater strain, especially when, as Georg Lukács points out, 'actions manifested in the external world now fail to account for the whole man, who in turn is not able to arrive at an action revelatory of his entire self'. ${ }^{23}$ Unlike previous forms of drama in which a character's words or actions would be understood by at least some of those who heard or saw them, both on stage and/or in the auditorium (thus, even in hostile Elsinore, Hamlet had confidence in his confidant, and knew he would be rightly valued and regarded by Horatio), the lack of a common language and a shared perception of the world in the late nineteenth century now inhibited such direct communication. Even if a character were to find the rare words capable of expressing what is essential to him (or her: Hedda Gabler's desperate attempt at articulating, in her references to the vine-leaves in Løvborg's hair, the values she is unable to 
live by is a typical case, as is the incomprehension with which she is viewed by her husband and Judge Brack following her suicide), 'these words will at any rate go unheard past the spirits of others, or reach them with meaning transformed'. ${ }^{24}$ Hence the notion which is continually advanced by Beckett's characters and frequently argued by Strindberg in (for instance) The Ghost Sonata, that true meaning resides in silence that 'can conceal nothing' and where 'you can hear thoughts and see the past' [SV 58, 205], a notion that was expressed most pointedly by Maeterlinck in an essay in Le Trésor des humbles (1896), of which Strindberg thought so highly that he translated it into Swedish for his third wife, the actress Harriet Bosse. Maeterlinck's essay formulates the programme for a drame statique such as Beckett has since realized: 'It is idle to think that, by means of words, any real communication can ever pass from one man to another... words can never express the real, special relationship that exists between two beings. ${ }^{25}$

Moreover, as Peter Szondi argued, in his provocative thesis, Theorie des moderne Dramas (Frankfurt, 1956), what is involved in this process is in many respects a dialectical progression whereby elements which first arrive in the domain of content as a response to the historical situation become the defining formal basis of the later drama. Thus the increasing isolation and separation of characters, one from another, and their apparent inability to communicate with each other in Strindberg, Maeterlinck or Chekhov, is inscribed as the new formal orthodoxy in the work of Beckett and Pinter.

One strand of this process can be observed in the role played by the setting in each of these plays, where the sequestration of the characters within a single scene, the restrictions this imposes upon possible action, and the potentially undramatic isolation they endure (with Alice and Edgar abandoned by their servants and cut off from the other islanders anticipating the lonely and depleted world of Endgame, whose slow extinction is recorded in Hamm's story), identifies both plays as examples of a recurring form of cellular modern drama in which the physical limitations imposed upon the characters are matched by the formal structures each dramatist employs. ${ }^{26}$

It was in fact Naturalism which stimulated a renewal of interest in the scenic image. Once men were regarded as the products of their heredity and environment, the setting could no longer remain only a more-or-less stylized frame for the dramatic action. It had now to play a role comparable to the one performed by the author's descriptions of the milieu in the naturalist novel, which were conceived as an essential key to an understanding of the characters. Indeed, the setting almost became another character, as vital as the figures on stage and generally more able than they to influence events. Most frequently an interior, that familiar room with its fourth wall removed to expose the intimate lives of its inhabitants to view, this setting might well represent a reduction 
in what the theatre portrayed from the universal stage of (say) medieval drama to the confinement of the modern world. In its most accomplished manifestations, however (for instance, in those settings devised by lbsen for his dramas of contemporary life which John Northam has shown to be an integral part of the action of the play), ${ }^{27}$ it conveyed a tangible, living presence which Raymond Williams plays upon in remarking that 'They were, in the fullest sense, living rooms: places made to live in in certain ways: environments which both reflected and influenced their possibilities of life. ${ }^{28}$

Furthermore, these rooms not only soaked into the lives of those who lived in them, and afforded their customary inhabitants an appropriate habitat with which they merged and where they were territorially at home (hence the inevitability of Miss Julie's downfall when she strays onto unfamiliar terrain, in the servant-dominated kitchen), they also emerged as the most powerful, active elements in a drama in which the human figures became increasingly passive, since it was through this material environment that the underlying natural and social relationships which acted upon the lives of the characters which Naturalism depicted were rendered dramatically. Moreover, if (as Williams goes on to suggest) this generally private family interior is 'predominantly shown as a trap', it is because it is not merely 'the centre of significant immediate relations' - that lattice work of personal relationships between characters which Ibsen and Strindberg analysed so indefatigably and acutely - but the nexus of those 'larger determining forces operating beyond it, to be looked at from the window or to arrive as messages which would reshape these lives'. ${ }^{29}$ For within or behind these late-nineteenth-century dramas of private lives lies that distinction between living space and work place, between the domain of reality operating in the latter and what Walter Benjamin called the private citizen's 'box in the world theatre', ${ }^{30}$ that drawing room where, as Ibsen and Strindberg both demonstrated (ironically in a theatre which aspired to an illusion of reality), illusion was fostered.

But at the end of the century, in The Dance of Death as in Munch's paintings or Schoenberg's first claustrophobic atonal works, which shortly followed, the interior as the domain of private illusion and painful memory, inhabited by figures who sit like prisoners behind doors they have often closed upon themselves in their unwillingness to confront the truth, becomes the nightmarish scene of these characters' inner lives. This is the process that comes to light in The Pelican or lbsen's John Gabriel Borkman, in which the home has already become a prison; which is continued in a succession of major plays, of which Pirandello's Enrico Quatro (1922), Sartre's Les séquestres d'Altona (1959) and Huis clos (1945), and O'Neill's Mourning Becomes Electra (1931) are only four of the most prominent; and which is now discernable in the series of abodes (no longer for living, but for dying in) which make up 
Beckett's universe, from 'the familiar chamber. At the far end a window. On the right the indispensable door', ${ }^{31}$ observed in Ghost Trio, to the more peculiar residences of Winnie's heap of sand in Happy Days, the urns in Play, Krapp's den, the dustbins in Endgame or Clov's chess square of a kitchen, 'ten feet by ten feet by ten feet' [p. 12].

It is, of course, not difficult to relate this process to those models of the mind's activity currently being established by Freud, where a topographical metaphor comprising the cellar, living room and attic of an average bourgeois dwelling house seems quite appropriate. And indeed there is already, in The Wild Duck (1884) in the late Naturalism to which Freud was in fact deeply indebted for the direction of his own project, an attempt to distinguish visually between the oneiric realm of the attic as a timeless universe of the imagination resembling the world of dreams, the mundane living room in which the Ekdals conduct their everyday relationships, and the drunken appetites let loose downstairs. What occurs alongside the withdrawal behind closed doors from John Gabriel Borkman (1896) onwards is thus a foregrounding of this inner landscape as the dramatist responded to the increasing fin-de-siècle preoccupation with what was variously called 'the soul', 'l'âme', 'Die Seele', 'själen' or 'sjælen', and moved from the visible to the invisible in pursuit of what Knut Hamsun described as 'the unconscious and even today almost totally uninterpreted life of the soul'. ${ }^{32}$

Thus it was in keeping with this trend that when Reinhardt chose to open his Kammerspiele in 1906 with a production of Ghosts he should appoint 'der Seelenmaler' (the soul-painter), Edvard Munch, to design the set for what had hitherto been regarded as the quintessentially naturalist stage drama. The interior into which the spectator was now invited to look was no longer a room but a personal and unconscious world of dreams and nightmares, and the way was open for a conception of the theatre as what Ionesco would later term 'the projection onto the stage of the world within', adding: 'it is in my dreams, my anguish, my dark desires, my inner contradictions that I reserve the right to find the stuff of my plays' ${ }^{33}$

But what is particularly to the point here is that those works in which this process is carried furthest, where the Chekhovian or Strindbergian concern with the failure of social communication, tedium and estrangement are, as it were, distilled in the alembic of form, come to resemble the rotunda in which Hamm and Clov are confined, hermetically sealed to the world without. With its self-conscious awareness of itself as a dramatic text, Beckett's theatre - and Endgame in particular - refers not to a world elsewhere but to itself. Even in chamber plays like The Ghost Sonata and The Pelican the text, however loaded with significance and suggestive power, points directly back to the recognizable social context which underlies the events of the drama - the crisis of bourgeois family relationships in The Pelican, for example, and the more 
extensive network of deception and corruption which sustains a society where Hummel's vampirism functions according to modern capitalist methods of psychological and economic exploitation, in The Ghost Sonata. Vestiges of this approach remain in Endgame, notably in Hamm's laboriously composed and unreliable narrative, but like the way in which the play treats another of the standard topics of bourgeois drama, the conflict between the generations ('Accursed progenitor... Why did you engender me?' [pp. 15, 35]), it is done schematically, the information the text affords pointing not outwards towards the world but inwards upon itself, where each detail adds a further item to the rules of the game. The father-son or master-servant relationship of Hamm and Clov weighs no more heavily in the course of the evening than that one of them cannot sit nor the other stand. And where the universalizing thrust of Strindberg's plays is to establish the general social relevance of what is depicted on stage ('Secrets like these are to be found in every home' [XV, 354; 2, 735], he insists, in a letter introducing The Ghost Sonata to his German translator, Emil Schering), the pathos generated by Beckett's text is directed to a common natural predicament: 'She was bonny once.... We too were bonny - once. It's a rare thing not to have been bonny - once' [p. 31].

Thus the event dramatized in Endgame neither takes place offstage (like the sale of the estate in The Cherry Orchard) nor is enacted on it: the event is the text itself and its own performance - the weary end of a game in which the players are painfully aware of the conventions governing stage dialogue in a theatre where no communication is possible. 'Something is taking its course,' Clov remarks portentously [p. 17], but what little linear movement that remained in The Dance of Death is abandoned here. There is no rising action nor falling action for, as Richard Goldman remarks, 'all is fallen at the play's opening. ${ }^{34}$ The first tableau is the last one, or rather, poised to depart Clov remains on stage, in position to recommence the play the following night. As Estragon remarked perceptively, on a previous occasion: 'Nothing happens, nobody comes, nobody goes, it's awful'. ${ }^{35}$ Although Clov perceives a boy outside, the latter never makes his way onto the stage where, throughout the play, 'there has not been a change of heart, mind, situation, venue [and the fact] that we are no closer to a reasoned grasp on the characters' natures or the meaning of what they enact, makes us wonder if it is truly a drama we are looking at - a work that unfolds in time and space.' 'Do we not feel,' Goldman concludes by asking, 'that we are in the presence of a linguistic form that nevertheless suggests the properties of non-linguistic forms - painting and music?'. ${ }^{36}$

Certainly Beckett has found it easier, as in the Three Dialogues with Georges Duthuit, to discuss his own situation in terms of abstract painting, and the musical analogy, already relevant to the thematically organized A Dream Play or to the Chamber Plays, in whose collective title the notion of music is deftly 
merged with a sense of confined inner space, is likewise relevant to Beckett's theatre for small groups of players or solo performance, a theatre in which, by his own account, he is searching for 'the kind of form that you find in music, for example, where themes occur'. ${ }^{37}$

Moreover, in both his last pieces for the theatre and in his own productions of the earlier plays, Beckett stressed both their musical nature and the composition of a stage image ideally apprehended in a moment of time and left to resonate in the spectator's mind.$^{38}$ Nevertheless, this theatre of stasis, of isolation and non-communication remains the descendant of that earlier, seemingly more vigorous theatre, in which these subjects first manifested themselves as a matter of acute concern. And this is not only because of the way in which Beckett's plays evoke Maeterlinck's haunting images of the blind man immobile in his chair and the menacing closed door, or Strindberg's Mummy become a reified turn of phrase as the old parrot she resembles in The Ghost Sonata, much as Nagg and Nell are the decrepit trash of Endgame: rather, it remains pertinent, given Szondi's insight into the way that concerns first made themselves felt in drama as a matter of content become questions of form in the following period, to perceive that alongside the music hall, Yeats, Racine, Jarry and all the other influences that have been discerned in Beckett's theatre, there remains a link with Naturalism.

For although in a radically reduced and depleted state, this theatre is ultimately an epigone of late-nineteenth-century drama. Beyond the similarities already adduced here between The Dance of Death and Endgame, the latter, with its succession of ends and the steady removal of its basic props (nature, biscuits, pap, coffins, etc.) epitomizes, even parodies, the 'falling curve' common to many naturalist works (The Father, Miss Julie, Germinal, L'Assommoir, Germinie Lacerteux, Niels Lyhne) to which Rilke once drew attention in his comments on J. P. Jacobsen's classic naturalist novel, Fru Marie Grubbe (1876). ${ }^{39}$ Life on what Krapp calls 'this old muckball', ${ }^{40}$ in a world without transcendence where personal decay parallels decline and fall, conjures up throughout Beckett's work images in keeping with Edgar's initial conviction that 'once the [human] mechanism's done for... there's hardly so much as a barrowload of muck to tip on the garden' [SV 44, 42]. In what Beckett's Molloy described as 'a world collapsing endlessly... a world at an end', 41 and which Lucky, in Waiting for Godot, perceived as a place where man 'in spite of the strides of alimentation and defecation is seen to waste and pine' in a universe that 'for reasons unknown' continues to 'shrink and dwindle, ${ }^{42}$ the naturalist writer would in fact recognize a familiar landscape. However, whereas Edgar sought to console himself for the absence of meaning in this malodorous universe by inserting himself into the cycle of continuing process of new life from death, Beckett's creatures exist in a situation where, however 
decrepit they become, they cannot obtain their release. The naturalist at least believed, like Jacobsen's hero in Niels Lyhne (1880) that there was an end, that it was possible 'to die the death, the bitter death'. ${ }^{43}$ Beckett's figures remain denizens of a text that goes on revolving, both on the page and in the mind. 